\title{
Structural Competitiveness of The Tourism Sector in Morocco
}

\author{
Camelia El Aouami and Abdeljalil Louhmadi
}

\begin{abstract}
The development of the tourism sector in Morocco is faced with a double challenge of competitiveness and attractiveness. In order to strengthen these two variables, it is necessary to adopt an analytical approach which is based on regional advantages of the country according to an integrated territorial dimension. The main challenges of this approach revolve around the developed tourist accommodation capacities, both quantitatively and qualitatively, internal micro-projects, small and medium-sized companies able to carry out concrete actions to develop the sector competitiveness, and to counteract poverty.

In order to answer to the aforementioned challenges, the Moroccan government, under the high patronage of HM the King, is conducting a prospective study on Moroccan tourism by 2030 with a view to capitalize on the 2020 and 2010 visions' achievements. Both first visions are part of a structuring approach in terms of employment, namely Azure 2020, Patrimony \& heritage, Eco \& sustainable development, Animation, Sports \& leisure and Biladi - Internal tourism. However, the Vision 2030 is not just function of incomes and prices, but other long term change factors that may affect or associate with human needs.
\end{abstract}

Index Terms - Attractiveness; competitiveness; good governance; development; knowledge society; tourism.

\section{INTRODUCTION}

Tourism, a sector that generates jobs and foreign exchange, could also offer Morocco the opportunity to acquire a key resource for its development; the economic contribution of tourist activity in Morocco is certainly important. It is increasingly seen by senior officials as a strategic sector to support economic development. However, tourism actors in Morocco still seem little mobilized on concrete sustainable tourism projects. Indeed, economic sustainability still wins out. It is true that a certain number of persons in charge and actors of tourism strive to offer products respecting better the human being and his environment.

The main objective of this article is to explore the aspects, which will make tourism a driving force for sustainable development in Morocco.

Also, the methodology used consists in describing the developments plans for tourism sector as well as the expected results.

\section{THE CHALLENGES OF THE ATTRACTIVENESS OF TOURISM INVESTMENTS IN MOROCCO}

\section{A. Strengthening the country's competitiveness}

The issue of attractiveness is first of all linked to certain additional costs and certain high levels of remuneration. It is in this sense that professionals in the sector are calling for public investment incentives to promote a specific system of interest rate subsidies for tourism investments. It would therefore be necessary to revise the taxation basis and social charges as well as the pricing of private operators.

It is with this in mind that a loan entitled "Azur crédit" with reference to the Azur Plan was launched by some local banks at a fixed rate over a period of fifteen (15) years in order to encourage the investors to invest in the area.

As a result, the strengthening of the competitiveness of the tourism sector in Morocco is based on the adoption of an analytical, exhaustive and rigorous approach, based on the strengths of the regions according to a territorial integrated dimension, inspired by the willingness to continue to make tourism as one of the economic engines, as a social and cultural development of the country.

B. Increase and diversification of reception and accommodation capacities

Reception capacities must be strengthened in three main segments: luxury hotels in exclusive tourist areas, business and leisure hotels in new tourist resorts, and tourist hotels and accommodation in main tourist areas, particularly seaside resorts. For this purpose, investment projects on the coast, among others, are encouraged with the promotion and technical assistance for tourism investments, as shown by the experience of the Azur Plan.

Such an increase in tourist accommodation capacities would make it possible to increase the duration of the target stays, so as to include a large part of classic seaside stays, but also of circuits and visits. In 2019, each tourist spent nearly 2.7 nights in a classified hotel establishment.

On the other hand, cooperation with neighbouring countries including Spain, for the realization of joint products could constitute a new prospect for the private sector, although joint circuits are often limited to small accompanied groups and at higher prices.

\section{Development of micro-projects and tourism SMEs}

The development of internal tourism micro-projects and small and medium-sized enterprises (SMEs) would allow the implementation of concrete actions to strengthen the country's tourism competitiveness, and to fight against poverty as a result. Some of these projects have already been completed, in this case the Vallée des Roses, which has a 
certain particularity in terms of the region georgraphy and its nature.

At the same time, the creation of "eco-resorts" could constitute real opportunities for SMEs by making it possible to receive tourists in small traditional structures with local development programs.

The success of this type of initiative is conditioned by the obligation of the Ministry of Tourism to make the granting of aids and facilities dependent on the respect of the criteria of sustainable tourism, according to the international standards in force.

\section{THE STRATEGIC VISION OF THE TOURISM SECTOR IN MOROCCO}

In accordance with the High Royal Guidelines and in a logic of capitalization on the achievements of the 2010 Vision, the Moroccan government has initiated a real cooperation process with public and private partners in order to develop the strategic vision of the sector for 2020 .

\section{A. The 2020 Vision and its various structuring programs} 2020

The 2020 Vision adopts an analytical, exhaustive and rigorous approach. It is inspired by the desire to switch to a structuring regional planning approach in terms of jobs and to develop the competitiveness of Moroccan tourism based on the strengths of the regions according to a territorial and integrated dimension.

Commitment: "Continue to make tourism one of the engines of economic, social and cultural development in Morocco"

The deep and rapid transformations of the country as a whole over the past ten years, the solid foundations laid by Vision 2010 and the opportunities offered by new trends in world tourism, allow us to nurture great ambitions for the new decade, based on:

- Authenticity: an approach that promotes the preservation, conservation and enhancement of the Kingdom's cultural and natural heritage;

- Diversity: the ambitious regional planning policy resulting from the 2020 vision was able to enhance this value;

- Quality: the deepening of the culture of the tourist service and the development of a convincing entertainment offer are relevant progress at this level;

- Sustainability: sustainable development is at the heart of the Kingdom's tourism concerns, given the considerable potential for differentiation in a prospective competitive environment.

The ambition of this vision was for Morocco to be one of the 20 largest global destinations and to establish itself as a benchmark in the Mediterranean area in terms of sustainable development.

Its main objective was to double the size of the sector by achieving the following specific objectives:

- Doubling the accommodation capacity by the construction of 200,000 new beds, and consequently doubling of tourist arrivals.

- Tripling the number of domestic trips.

- Creation of new direct jobs throughout the national territory, to employ at the end of the decade nearly a million
Moroccans.

- Increase in tourism receipts to reach a cumulative over the decade of nearly Dh1.000,bn.

- Increase of 2 points the share of tourism GDP in the national GDP to reach nearly Dh150bn.

In order to materialize this ambition and achieve these objectives, the development of the sector should be carried out along three main axes:

- An equal distribution of the sector wealth between the different regions of the country by promoting a policy of territorial development of the tourist offer.

- Dynamics and leadership are required for a new tourism governance structure.

- Respect for the environment and socio-cultural authenticity as part of an integrated sustainable development approach.

In accordance with the aforementioned objectives, six structuring programs have been defined to increase the attractiveness of destinations:

- The Azur 2020 program: consists of building an internationally competitive Moroccan seaside offer through the repositioning of the various seaside resort projects already launched, by strengthening the entertainment and leisure offer, and integrating the various ecological aspects.

- The Patrimony \& Heritage program: aims to enhance our Moroccan cultural identity by highlighting our tangible and intangible heritage. The program provides for:

- The rehabilitation and conversion of historical monuments.

- The design of interpretation circuits through the medinas of the large imperial cities.

- The creation of a tourism heritage enhancement company to take advantage of the architectural heritage.

- The creation of great museums of international class, including that of Africa in Tangier and that of the History of Morocco in Meknes, would be recognized like the great museums in Europe.

- The dispersion of an animation offers in festivals of regional traditions, which would be managed by the Foundation of Festivals of Traditions.

- The Eco \& sustainable development program: manifests itself in the development of the "carbon neutral" Ouarzazate site as the leading African energy production destination to offset the $\mathrm{CO} 2$ emissions generated by all local economic and tourist activities;

- The Entertainment, Sports \& Leisure program: concerns the creation of a rich, varied entertainment offer that complements basic tourist infrastructures.

- The Internal Tourism program - Biladi: aims to meet the expectations of national tourists through the consolidation and completion of plans already launched over the past decade, namely the creation of 8 tourist resorts, the addition of 'a new "Center Atlantique" resort, the creation of new outdoor holiday villages as well as the development of the national plan for outdoor accommodation aimed at improving the quality of the current offer. 
B. New strategies for 2030 leading to diversification of the source market

As tourism is an essential component of the complex socio-economic systems of industrialized countries, certain major trends influence the quantitative and qualitative evolution of demand in the sector both nationally and internationally. In other words, tourism demand is not only a function of income and prices, but other long-term drivers of change may affect or be associated with human needs, which factors must be identified and taken into account considerably in the vision 2030, which includes a generational change.

Our analysis at this level requires a reminder of the new trends and the factors of change incorporated in them, in order to be able to interpret the different scenarios of 2030 vision.

We raise the two main and main trends: new functional technologies, and the knowledge and knowledge society.

Most of today's functional innovations revolve around three technological fields, the field of computing, that of telecommunications and that of micro-electronics. These new technologies are invisibly incorporated into the deep needs of tourists, allowing them easier and faster access to the various goods and services in the sector.

On the commercial front, recent systemic changes provide applicants with the flexibility to select offers according to the quality / price ratio that suits them. As a result of this type of innovation, new formulas are developing such as:

- "mid - week": short weekend stays.

- "click \& pack": product assembly.

- "on the fly": combination of the individual trip and the packaged trip.

- "early booking": if you book early, the price is cheaper.

In terms of transport, particularly air transport, systemic innovations play the role of remedying distance constraints and facilitate medium and long-distance travel.

In terms of telecommunications and IT, the tourist is able to access more easily the essential elements of his lifestyle which were previously lacking, in this case, health, the education system, training, etc. work... remote services allow tourists to continue living as if they have never left their main residence.

Vision 2030 puts these trends at the heart of its concern to bring tourism supply closer to the psychological expectations of demand and to ensure continuous improvement.

\section{- The knowledge society}

Knowledge and knowledge trends take on the need to segment tourism demand according to age groups and the cultural specificities of the events, and to form market niches with high added value. These same tendencies characterize the behaviour of the tourist by a high rigor in the evaluation of the services obtained and a more precise precision in his request. Finally, all these transformations towards the knowledge and knowledge society are driving the demand from tourists towards a developed sensitivity for ecological balance and the quality of the environment.

Generally, the new variables forming the demand for tourism in such a society currently make tourism a sustained service providing a vital element in the quality of life, which requires a permanent improvement in the quality of infrastructure, tourism equipment and components.

Two major trends are imposed on the variables of the tourist offer: globalization and sustainable development.

\section{- Globalization and integration}

The scourge of globalization, financial, economic, commercial, environmental, scientific, technological or computer science, has allowed the increase of foreign direct investment flows, and as a result, companies have started to develop new unified strategies thus crystallizing territorial competitiveness, and imposing new political challenges.

Indeed, global regionalization makes it possible to unify market conditions in certain areas, all the more so to increase competition between investors in the sector.

In the same vein, the traditional sharing between the various infrastructures and the productive systems gives rise to public / private partnerships in the tourist installations.

\section{- Sustainable development}

Seeking to establish synergies between economic return, social equity and the preservation of nature, the concept of sustainable development today imposes new trends to be taken into account in future perspectives:

- The incorporation of social and environmental costs in the prices of tourist goods and services offered in order to favour the most sustainable ones.

- Consideration of the values mentioned above at the level of demand.

- New technologies also as an essential instrument to achieve the objectives of this development, namely innovation and economic growth, creativity and human development, environmental protection and ecological balance.

\section{- The factor of change}

The drivers of change form a variable which can either reinforce or influence the above trends. Moroccan tourism is potentially favoured by the following change factors:

- Consolidation of public - private partnerships already provided for in vision 2010 .

- Improving the supply of tourist infrastructure in Morocco by reducing the prices of air transport between Spain and Morocco, thus opening the door to European arrivals in Morocco.

- The relocation of Spanish tourism caused by the saturation of tourist areas such as the Costa del Sol and the Canary Islands, favours the destination for Moroccan tourism thanks to its proximity.

- The requirement at the level of demand for domestic tourism forces the adaptation and modernization of Moroccan domestic tourism.

The integration of these factors in the new trends which influence the supply and demand of tourism in Morocco leads to the development of the constitutive scenarios of the new vision in the ten years to come.

\section{Long-term scenarios for tourism 2030}

The first scenario follows a known path, it is the successful experience of other similar countries. It is essentially based on the success of the seaside resorts of the Azur plan achieved by Vision 2010, and which is also based on the aforementioned change factors.

This scenario mainly considers the increase in average 
household income and targets the expansion of second homes, the housing of which is distributed both between seaside resorts and on historic urban sites. This result in a multiplier effect on the Moroccan economy estimated to be greater than traditional tourism, being a scenario with high growth in tourist flows. The realization of this scenario is conditioned by the activation by the government of infrastructure programs, such as the airport (increase in the number of lines with the originating markets), the NorthSouth highways and the fixed link, Morocco-Spain.

In this same perspective, funding plays a key role and should call on the government to encourage the involvement of international capital, in particular European capital which is part of the Spanish tourism relocation project, and to develop the different types of collaborations. with Moroccan capital.

The second scenario, differently from the first, is more concerned with the new trend in knowledge and knowledge of current and future society. It is indeed a question of aligning itself with the general orientation in the Mediterranean outlined by the Blue Plan (UNEP) for 2025 which develops a prospective of collaboration between 27 Mediterranean countries.

This scenario is essentially based on public action. As already mentioned, it requires the integration of the three pillars of sustainability: social, economic and environmental.

- On the social level: the financial contribution of sustainable tourism to improving the living conditions of poor populations is reflected in the productive strategy in Morocco. This scenario provides for the development of internal and rural tourism which is a source of income for agricultural and artisan populations.

Likewise, it brings a certain modernization through developments in other productive sectors such as renewable energies.

- On the economic level: this scenario allows a certain diversification in the source markets, synergies with other sectors of activity such as fishing, agriculture, craft industry, ... the emergence of ecological taxation as new fiscal financing instruments, the participation of the third sector, and the encouragement of the concepts of companies with social responsibility.

- Ecologically: this program prioritizes the protection of the Mediterranean coast through the development of parks and nature reserves, the treatment of residues, and other regional sustainable development projects.

The third scenario is geo-strategically based on the integration of neighbouring European countries with a view to strengthening the Euro-Mediterranean partnership. It provides for the development of infrastructures capable of facilitating this collaboration, namely means of transport and telecommunications, public health, and education equipment.

This scenario envisages on the one hand an important advance in the management and integration of EuroMediterranean links, on the other hand, the benefit of technological content in possession of which the Moroccan sector does not currently have, but which has a great potential to be exploited in this scenario. However, the feasibility of this scenario remains conditioned by the immediate actions of foreign economic agents.

The fourth scenario constitutes the common zone which corresponds to a minimal scenario of important appearance. The first scenario devotes its particularity to mass tourism, the second to sustainability and the fourth to knowledge tourism.

It refers to both mass and quality tourism, with a significant volume of income, taking its funding from both the public sector and the local and foreign private sector, promoting a large and diversified range of products, ranging from traditional to the most modern and targeting source markets of different origins around the world.

\section{ANALYSIS AND INTERPRETATION, THE ACHIEVEMENTS OF THE 2020 AND 2030 VISIONS}

Behind the two aforementioned strategic visions, I find that Moroccan tourism, on the strength of its achievements and those of these visions, has relatively succeeded in amplifying the factor of attractiveness of tourism investors from both national and international origin.

In this sense, we are witnessing a growing interest from foreign operators in the sector, which is reflected in the large number of investment agreements signed each year with the Moroccan government. These conventions are in my opinion the best fruit of the scenarios and strategies mentioned in the preceding paragraphs. Ultimately, it is the real commitment of FDI players. Indeed, during the last two decades, here is the result of the agreements signed:

- In 1999, 4 agreements were signed with foreign investors; two were signed with mixed investors and only one with a Moroccan investor.

- In 2000, 6 agreements were concluded with foreign operators relating to the creation of new accommodation units, 1 agreement with a mixed investor and 1 other with a Moroccan.

- In 2001, 6 agreements were concluded with foreign investors, 4 with Moroccans and a mixed agreement.

- In 2002, 3 agreements with foreign investors.

- In 2003, 5 agreements with foreign investors.

From the number of agreements concluded, I note that the greatest importance is given to the foreign investor, while the Moroccan investor comes last. However, the Moroccan investor is better acquainted with the wealth of his country on all levels, natural, geographical, cultural, social, historical, civilization.

At this level, I recommend that the sector's operators should be conscious to explore both Moroccan and foreign investment capital.

It is a responsible nation that is committed to preserving its traditions and culture, and to adopting the values and principles of modernity and sustainable development thanks to its human, cultural and natural capital.

It is in this perspective that Morocco should capitalize on these specificities and particularities enjoyed by the Moroccan people and become one of the largest global. 


\section{CONCLUSION}

In fine, we can conclude from the favourable international positioning of Morocco in tourist attractiveness that the state strategies implemented have led to positive results, according to the index bloom consulting country ranking 2017 where Morocco ranks $38^{\text {th }}$ on 193 countries in the word.

Also, the development of new information and communication technologies and the emergence of the knowledge society should, moreover, continue to have an increasingly strong propensity to modify qualitatively and quantitatively the tourist demand and to raise the level of sensitivity to ecological costliness, to the quality of the environment and to the cultural dimension of tourist products.

\section{ABREVIATIONS}

SMES: Small and Medium Enterprises.

\section{REFERENCES}

[1] François Vellas and Zouhair Mehadji, « Les stratégies touristiques du secteur privé au Maroc », Téoros, 24-1 | pp.31-36,2005.

[2] HMIOUI, Aziz, Attractivité du Maroc pour l'investissement direct étranger (IDE) : Cas de l'investissement touristique. Revue Marocaine de Gestion et d'Economie, [S.1.], n. Feb. $2^{\text {nd, }} 2016$.

[3] Myriam Donsimoni Le tourisme, facteur de développement local; Presses Universitaires de Grenoble, 1999.

[4] A. Agnouche, Le Maroc actuel: Une modernisation au miroir de la tradition?, Institut de recherches et d'études sur le monde arabe et musulman, September $18^{\text {th }}, 2013$.

[5] Tourism overview, turning of the tide, the report 2018, Oxford Business Group, AMDI, 2018.

[6] Tourism overview, great destinations, the report 2019, Oxford Business Group, AMDI, 2019.

[7] Lois Stevenson Développement du secteur privé et des entreprises: Favoriser la croissance au Moyent-Orient et en Afrique du Nord; edition ESKA ; UNC Press Books, 2012.

[8] Bernard Schéou Du tourisme durable au tourisme équitable: Quelle éthique pour le tourisme de demain? Edition De Boeck Supérieur, November $16^{\text {th }}, 2009$.

[9] Houcine Berbou, Aziz Fassouane, Mustapha Belaissaoui ;Proceedings of the 3rd International Conference of Economics and Management (CIREG 2016) Volume I; Cambridge Scholars Publishing, April $6^{\text {th }}$, 2020.

[10] Haut-Commissaire au Plan deMaroc, Ahmed LAHLIMI ALAMI,Tourisme 2030 Quelles ambitions pour le Maroc ?.

[11] OECD,Compétitivité et développement du secteur privé : Maroc 2010 Stratégie de développement du climat des affaires : Stratégie de développement du climat des affaires.2011.

[12] OECD, Les voies de développement Examen multidimensionnel du Maroc (Volume 2) Analyse approfondie et recommandations: Analyse approfondie et recommandations OECD Publishing, May $14^{\text {th }}, 2018$.

[13] OECD,Tendances et politiques du tourisme de l'OCDE 2018. OECD Publishing, June $19^{\text {th }}, 2018$.

[14] $\mathrm{La}$ stratégie de tourisme au Maroc; https://mtataes.gov.ma/fr/tourisme/mesures-dappui-a-lindustrietouristique/appui-investissement-touristique/.

[15] www.tourisme.gov.ma.

[16] www.doingbusinessibs.it.

[17] www.ec.europa.eu.

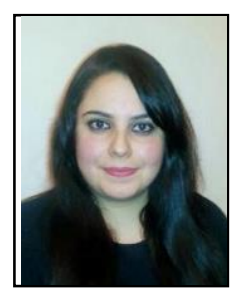

\section{Camelia EL AOUAMI}

Born in Tangier, Morocco on the $22^{\text {nd }}$ of September, doctoral student in economics and management at the faculty of law, economics and social sciences of Tangier (FSJEST) University Abdelmalek Essâadi, Morocco.

Member of a research group in finance, economy and development.

She holds a specialized master's degree in economics in 2012 at the FSJEST. and management option finance, banking and markets

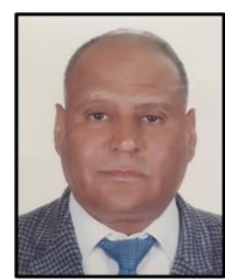

\section{Abdeljalil LOUHMADI}

Doctor in Geography and Professor of Territorial Management and Sustainable Economic and Social Development at the Department of Economics and Management at Faculty of Law, Economics and Social Sciences of Tangier (FSJEST) - Abdelmalek Essâadi University - Morocco.

$\mathrm{He}$ is trainer of regional and local Elected Officials, Consultant and Expert with social organizations, supporting and creating the associative project.

Also, he is the head of the Group of research and studies in sustainable development, being a referent of Networking at Abdelmalek Essâadi University. Besides, he is a Founding member of the Club des financiers du Nord and a member of the national observatory for higher education and scientific research. 